\title{
15 Langkah Demi Langkah Jalani Profesi Kepala Sekolah
}

\section{Yuli Hutami Ningrum}

Universitas Nahdlatul Ulama Sidoarjo

\section{Pengantar}

Anda baru saja menerima posisi Kepala Sekolah baru. Atau, anda baru saja mendirikan sekolah baru sehingga menjadi wirausahawan pendidikan. Semua untuk manajemen pendidikan. Anda bersemangat! Anda telah bekerja keras selama bertahun-tahun untuk bersiap. Anda merasa luar biasa tetapi juga sedikit gugup. Bagaimana dengan hal-hal yang tidak Anda ketahui! Bagaimana dengan tantangan yang akan Anda hadapi! Apakah Anda menebak-nebak diri sendiri?. Ketika saya memulai posisi Kepala Sekolah pertama saya, saya sangat bersemangat. Yah, saya membuat kesalahan saya di sepanjang jalan, tetapi untungnya saya memiliki mindset berkembang 
dan belajar banyak. Setiap posisi kepemimpinan saya telah memberi saya tantangan dan kesulitan. Ketika saya merenung, melalui masamasa tersulit saya yang paling saya pelajari. Jadi, inilah kiat sukses saya untuk Anda ketika Anda mulai sebagai Kepala Sekolah atau pemilik sekolah yang baru. Untuk orang-orang yang cinta pendidikan, yang mau berjalan lebih jauh untuk merasakan kesuksesan pemimpin yang sulit dipahami, berikut adalah beberapa tips untuk mengelola sekolah bagi kepala sekolah dan wirausahawan pendidikan yang serius.

\section{Jadilah Inspirasi}

Dalam minggu-minggu pertama Anda berbicara dengan guru, siswa dan orang tua dengan pidato tentang kemungkinan pendidikan yang mulia, menyoroti visi dan misi sekolah.

Ciptakan antusiasme dan optimisme untuk bekerja bersama dalam menciptakan arahan masa depan untuk sekolah. Lanjutkan fokus ini melalui Kepala Sekolah Anda (Driscoll, 2018). 


\section{Pimpin Kelompokmu}

Pendidikan Indonesia membutuhkan peningkatan akses, mutu dan relevansi pendidikan untuk memberi manfaat membangun bagi pendidikan dan rakyat Indonesia (Irawan et al., 2018). Teriakan lain untuk Seth di sini. Dia menawarkan pandangan yang menarik tentang kepemimpinan dalam bukunya Tribes. Orang membutuhkan koneksi, komunitas, dan pemimpin. Sudah waktunya bagi Anda untuk meningkatkan dan melakukannya dengan integritas (Bauer, 2019).

\section{Kelilingi Diri Anda dengan Guru yang Baik}

Mempekerjakan guru yang baik membuat pekerjaan kepala sekolah lebih mudah di hampir setiap aspek. Guru yang baik adalah pendisiplin yang solid, mereka berkomunikasi dengan baik dengan orang tua, dan mereka memberi siswa mereka pendidikan yang berkualitas. Masingmasing hal ini membuat pekerjaan kepala sekolah lebih mudah. Sebagai kepala sekolah, 
Anda ingin bangunan yang penuh dengan guru yang Anda tahu sedang melakukan pekerjaan mereka. Anda ingin para guru yang 100\% berkomitmen untuk menjadi guru yang efektif dalam setiap aspek. Anda menginginkan para guru yang tidak hanya melakukan pekerjaan mereka dengan baik tetapi bersedia untuk melampaui dan melampaui persyaratan inti untuk memastikan bahwa setiap siswa berhasil. Sederhananya, mengelilingi diri Anda dengan guru yang baik membuat Anda terlihat lebih baik, membuat pekerjaan Anda lebih mudah, dan memungkinkan Anda untuk mengelola aspekaspek lain dari pekerjaan Anda (Meador, 2019).

\section{Semangat untuk Langit}

Guru harus bisa membangun generasi muda untuk masa depan. Hiduplah untuk mengamalkan ilmu (Sholichah, Istiqomah, Rosyidah, \& Purnomo, 2017). Pendidikan adalah kunci untuk membuka pintu emas kesuksesan. Wirausaha pendidikan dengan motivasi bisnis 
dengan Allah Ta'ala sebagai bentuk kenyamanan untuk ibadah. Tips mengelola institusi pendidikan adalah niat mendidik dan berjuang karena Allah ta'ala. Niscaya rintangan sebesar apapun akan terasa ringan dihadapan kita. Melihat anak mengenal Allah Ta'ala dan sukses akhlak dan pengetahuannya merupakan kebahagiaan pendidik (Yuniarti, Kautsari, Sholichah, Purnomo, \& Rosyidah, 2017). Prinsip pendidikan adalah sosial. Sebagai seorang guru, kita harus memiliki kepedulian sosial (Asitah et al., 2017). Setiap manusia hamba Tuhan yang memiliki ilmu selayaknya harus mengamalkan ilmu tersebut (Asitah et al., 2017).Hubungan pendidikan antara guru dan murid itu seperti aliran listrik dengan lampu. Bagaimana lampu itu bisa menyala kalau aliran listriknya juga mati ?. Bagaimana murid itu bisa berprestasi sedangkan guru sendiri tidak pernah berprestasi dan mendoakan (Fidiana, Istiana, Rosyidah, \& Purnomo, 2017). 


\section{Kebijakan Pintu Tertutup}

Anda mungkin pernah mendengar tentang kebijakan pintu terbuka, atau Anda bahkan mungkin memilikinya sendiri. Meskipun mengakomodasi untuk memungkinkan staf Anda dan mungkin bahkan siswa masuk ke kantor Anda sepanjang waktu, itu juga membuat Anda tidak menyelesaikan pekerjaan dan tetap konsisten. Memiliki kebijakan pintu tertutup untuk setidaknya sebagian dari hari Anda akan memungkinkan Anda untuk fokus pada tugas kerja. Tetapkan jam kerja yang ditetapkan dan komunikasikan jadwal Anda kepada anggota staf dan siswa. Dorong staf dan siswa untuk menjadwalkan waktu bersama Anda sebelumnya jika memungkinkan. Menjaga jadwal harian akan membantu Anda mengatur waktu Anda lebih efektif dan menghindari gangguan (Kerns, 2016).

\section{Menjadi Profesional}

Siswa perlu memahami apa yang diketahui dan apa yang diminta untuk memiliki kemampuan 
menjawab (Suci et al., 2018). Daripada menjadi guru yang terlalu ramah, cobalah menjadi mentor yang baik. Interaksi harus dibuat ramah tetapi tidak akrab (Edsys, 2016).

\section{Setelah Anda berjalan melintasi ambang} Kepala Sekolah, hubungan berubah.

Ketahuilah bahwa Anda sekarang dipandang sebagai otoritas tertinggi di sekolah oleh orang tua, mantan kolega, dan siswa (Drewitt, 2017). Pemimpin sekolah dan wirausaha pendidikan seharusnya senantiasa menikmati proses karena tidak ada hal yang besar yang tidak dilakukan dari hal yang kecil. Semua butuh proses, karena kesuksesan tidak datang secara langsung tanpa berproses (Maula et al., 2017).

\section{Prinsip Wirausaha}

Edupreneur atau educational entrepreneur berasal dari dua kata yaitu education bermakna pendidikan dan entrepreneur bermakna pengusaha atau 
wirausahawan. Ada juga yang menyamakan istilah edupreneur dengan istilah teacherpreneur (Purnomo, 2017). Toleransi, bekerja sama, bertanggungjawab, dan amanah adalah prinsip wirausaha pendidikan (Nahdiyah, Amrina, Purnomo, \& Rosyidah, 2017). Menjaga hubungan baik dengan wali siswa melalui melaksanakan janji dan pelayanan yang baik adalah bagian dari promosi wirausaha (Asitah, Usmawati, Rosyidah, \& Purnomo, 2017).

\section{Tetapkan Nilai-Nilai Anda ... dan Berpegang Teguhlah pada Mereka}

Manajemen sekolah dilakukan dengan menerapkan standar kualitas dalam rekrutmen pengajar yaitu kedekatannya dengan amaliyah (Munjidah, Zannah, Purnomo, \& Rosyidah, 2017). Apakah Anda tahu apa yang Anda perjuangkan ... apa yang paling penting bagi Anda? Tulis nilainilai Anda. Poskan di dinding kantor Anda dan hidupkan di luar (Bauer, 2019). kesabaran dan komunikasi yang baik dengan masyarakat sekitar 
adalah kunci untuk dapat mengatasi masalah dan bisa bangkit dari keterpurukan manajemen pendidikan. Prinsip utama dan kepemimpinan wirausaha pendidikan adalah disiplin, kreatif, cerdas dan ulet (Qori'ah et al., 2017).

\section{Jangan Mengubah Apa Pun di Tahun Pertama}

Fokus pada pembelajaran pribadi dengan mengamati dan membangun hubungan. Para guru membenci perubahan, jadi pastikan bahwa setiap perubahan yang Anda usulkan lebih baik layak dilakukan dan diakui oleh sebagian besar sesuai kebutuhan (Drewitt, 2017). Cara memimpin sekolah adalah senantiasa musyawarah serta sharing bersama para guru atau dengan siapapun dan tetap mendekat pada Allah SWT (Yuniarti et al., 2017). 


\section{Mengulas Pendidikan}

Cari ilmu yang bermanfaat dan patuhi aturan-aturan yang ada. Bijaksana dan pantang menyerah dalam belajar adalah kunci kesuksesan. Pendidikan adalah pelajaran yang harus kita pelajari setiap hari baik dari buku, lingkungan, teman, maupun keluarga agar kita tidak tertinggal (Qori'ah, Sholichah, Purnomo, \& Rosyidah, 2017). Pendidikan itu sebuah perhiasan dalam kemakmuran dan tempat bernaung dalam kesengsaraan (Maula, Mufidah, Rosyidah, \& Purnomo, 2017). Hasil penelitian menunjukkan bahwa penerapan pembelajaran dapat meningkatkan prestasi siswa; dan tes menunjukkan bahwa prestasi belajar siswa kelas belajar lebih baik daripada siswa kelas konvensional (Iskandar, Rizal, Kurniasih, Sutiksno, \& Purnomo, 2018). Guru merupakan seorang yag memilki tugas mulia sebagai pendidik dan pengajar sekaligus sebagai pembentuk kepribadian siswa (Maula et al., 2018). 


\section{Dapat Diakses}

Pemimpin, apakah mereka kepala sekolah atau ketua departemen, harus selalu bersedia dan dapat bertemu dengan guru. Orang harus diprioritaskan daripada dokumen. Itu mungkin berarti mendelegasikan masalah keuangan dan lainnya ke manajer tetap yang tidak bertanggung jawab atas prestasi guru dan siswa. Para pemimpin harus sangat ramah sehingga para guru merasa nyaman mendekati mereka dengan keprihatinan mereka. Mereka juga harus memperkenalkan diri kepada siswa dan mengingat nama mereka sehingga siswa menganggap mereka sebagai orang, bukan hanya penegak disiplin (Watanabe-Crockett, 2018).

\section{Gunakan Tiket Keluar untuk Terhubung}

Tiket keluar adalah alat yang bagus untuk meninjau dan memeriksa pemahaman, tetapi mereka juga bisa menjadi alat yang ampuh untuk menghubungkan. Ukuran kelas yang besar 
menjadikannya tantangan untuk berbicara dengan semua siswa Anda. Tiket keluar adalah cara untuk menunjukkan minat Anda sambil juga memberikan siswa format untuk dibagikan (Kane, 2018). Tips kelola sekolah adalah senantiasa belajar dan bekerja keras. Bersabarlah dengan masalah, sesungguhnya didalam kesulitan ada kemudahan (Sholichah et al., 2017).

\section{Tetapkan Waktu Reguler Untuk Pekerjaan Rumah / Kognitif}

Guru merupakan seorang pendidik dan pengajar sekaligus sebagai pembentuk kepribadian siswa yang unggul, berwawasan dan baik (Maula et al., 2018). Tetapkan waktu tertentu selama seminggu untuk pekerjaan rumah atau "waktu berpikir". Berkomitmen untuk saat ini. Ketika pekerjaan rumah selesai, waktu tambahan dapat digunakan untuk membaca, meninjau catatan, atau menghafal (Springer, 2019). 


\section{Mengelola dan Berbagi Data}

Pemimpin sekolah sebisanya tegas, toleran terhadap bawahannya dan mengayomi. Pendidikan adalah catatan masa lalu dan pengajaran masa kini untuk masa depan bangsa. Pendidikan adalah menyampaikan ilmu dan mentransformasi orang lain menjadi lebih baik (Fidiana et al., 2017). Administrator sekolah harus membuat kelonggaran untuk platform yang akan digunakan di sekolah mereka yang akan membuatnya lebih mudah bagi semua pemangku kepentingan untuk mengelola data dan membagikannya juga. Dengan menggunakan platform seperti itu mereka akan dapat menjaga data yang berkaitan dengan siswa. Ini akan sangat bermanfaat bagi para guru karena mereka sekarang akan memiliki akses ke nilai, kehadiran, nilai ujian, dan rincian penting lainnya dari siswa mereka. Melalui sistem berbasis dasbor seperti itu, Anda juga dapat meninjau dalam waktu singkat seberapa baik kinerja siswa Anda (Fedena, 2018). 


\section{References}

Asitah, N., Usmawati, D. Z., Rosyidah, E., \&

Purnomo, A. (2017). MI Hasyim Asy’ari IImu

Harus Terus Mengarus. In Wirausaha

Pendidikan Indonesia (Jilid 2). Sidoarjo:

UNUSIDA Press.

Bauer, D. (2019). 200 Tips for Effective School

Leaders. Retrieved June 11, 2019, from

https://www.betterleadersbetterschools.com/200

-tips-effective-school-leaders/

Communicator. (2017). 4 Time Management Tips for

Principals. National Association of Elementary

School Principals, 40. Retrieved from

https://www.naesp.org/communicator-june-

2017/4-time-management-tips-principals

Covey, S. (1996). First things first. New York: Simon and Schuster.

Drewitt, P. (2017). 25 tips for School Principals.

Retrieved June 10, 2019, from

https://www.linkedin.com/pulse/25-tips-school-

principals-paul-drewitt

Driscoll, M. (2018). 16 Success Tips for New 21st

Century Principals. Retrieved June 23, 2019, from https://thinkstrategicforschools.com/16success-tips-new-21st-century-principals/

Edsys. (2016). 10 Awesome Tips to Manage School Discipline Issues. Retrieved June 27, 2019, from https://www.edsys.in/10-awesome-tips-tomanage-school-discipline-issues/ 
Educational Leaders. (2019). Guides for managing your school. Retrieved June 28, 2019, from http://www.educationalleaders.govt.nz/Managing -your-school/Guides-for-managing-your-school

Fedena. (2018). Quality tips for better school management. Retrieved June 24, 2019, from https://fedena.com/blog/2018/11/quality-tips-forbetter-school-management.html

Fidiana, W., Istiana, Z., Rosyidah, E., \& Purnomo, A. (2017). MINU Waru 2 Insan Berkilau Cahaya Manfaat. In Wirausaha Pendidikan Indonesia (Jilid 4). Sidoarjo: UNUSIDA Press.

Harris, S. (2019). 10 Survival Tips for New,

Struggling School Principals. Retrieved June 21, 2019, from https://www.teachhub.com/10survival-tips-for-school-principals Irawan, D. E., Purnomo, A., Sutiksno, D. U.,

Abraham, J., Alamsyah, A., Saputra, D. H., ... Rosyidah, E. (2018). Kajian Pendidikan Tinggi IDRI untuk DPR RI dan Ristek Dikti 2018. Bandung: ITB Press.

Iskandar, A., Rizal, M., Kurniasih, N., Sutiksno, D. U., \& Purnomo, A. (2018). The Effects of Multimedia Learning on Students Achievement in Terms of Cognitive Test Results. Journal of Physics:

Conference Series, 1114(1), 012019.

https://doi.org/10.1088/17426596/1114/1/012019 
Kane, A. (2018). 5 Essential Tips for Managing High School Students. Retrieved June 23, 2019, from https://theartofeducation.edu/2018/07/02/5essential-tips-for-managing-high-schoolstudents/

Kerns, K. (2016). 5 Time Management Tips for School Administrators. Retrieved June 26, 2019, from http://help.thesubservice.com/blog/5-timemanagement-tips-for-school-administrators Maula, I., Asitah, N., Munjidah, A., Nahdiyah, K., Yuniarti, D., Sholichah, S. A., ... Qori'ah, S. (2018). Kontribusi Kreativitas Guru SD dalam Induksi Pembelajaran.

https://doi.org/http://doi.org/10.17605/OSF.IO/B S795

Maula, I., Mufidah, F. I., Rosyidah, E., \& Purnomo, A. (2017). SD Antawirya Islamic Javanese School Mother is Culture. In Wirausaha Pendidikan Indonesia (Jilid 1). Sidoarjo: UNUSIDA Press. Meador, D. (2019). 10 Things a Successful School Principal Does Differently. Retrieved June 25, 2019, from https://www.thoughtco.com/things-asuccessful-school-principal-does-differently3194532

Munjidah, A., Zannah, I. P. N., Purnomo, A., \& Rosyidah, E. (2017). MI Thoriqussalam Berpegang Kepada Rosul. In Wirausaha Pendidikan Indonesia (Jilid 4). Sidoarjo: UNUSIDA Press. 
Murray, J. (2018). Time Management Tips for School Leaders - Part I. Retrieved June 25, 2019, from https://www.ccu.edu/blogs/cags/2018/01/timemanagement-tips-for-school-leaders-part-i/ Nahdiyah, K., Amrina, S., Purnomo, A., \& Rosyidah, E. (2017). SD Taman Pendidikan Islam Porong Iman Kuat Bekal di Akhirat. In Wirausaha Pendidikan Indonesia (Jilid 2). Sidoarjo: UNUSIDA Press.

Okoli, A. (2017). 3 Little Changes that Would Make a Big Difference to your School Management. Retrieved June 29, 2019, from https://safsms.com/blog/3-changes-to-improveschool-management/

Peel District School Board. (2019). Becoming an Effective Youth Leader. Retrieved June 20, 2019, from http://www.peelschools.org/students/studentacti vitycounci//tipsforbeingeffectiveschoolleader/Pag es/default.aspx

Purnomo, A. (2017). Pengertian Edupreneur. https://doi.org/10.31227/osf.io/8fnu6

Qori'ah, S., Sholichah, S. A., Purnomo, A., \&

Rosyidah, E. (2017). Progresif Bumi Sholawat dengan Kebenaran Semua Pasti Ada Jalan. In Wirausaha Pendidikan Indonesia (Jilid 3). Sidoarjo: UNUSIDA Press.

Sholichah, S. A., Istiqomah, A., Rosyidah, E., \& Purnomo, A. (2017). MI Darun Najah Berfikir Berkarya Berdzikir. In Wirausaha Pendidikan Indonesia (Jilid 3). Sidoarjo: UNUSIDA Press. 
Springer. (2019). Tips for Managing Organization.

Retrieved June 29, 2019, from

https://www.springer-ld.org/springer-

experience/center/parent-programs/tips-

organization

Suci, S. H. A., Rosyidah, E., Asitah, N., Aini, N.,

Murni, A. W., Anam, F., ... Kuraesin, A. D.

(2018). Learning from Picture and Picture Action

Research : Enhancement of Counting Ability on

Division of Numbers for Primary School

Students. Journal of Physics: Conference

Series, 1114(1), 012044.

https://doi.org/10.1088/1742-

6596/1114/1/012044

Watanabe-Crockett, L. (2018). The 10 School

Leadership Best Practices That Make a

Difference. Retrieved June 20, 2019, from

https://www.wabisabilearning.com/blog/10-

school-leadership-best-practices

Yuniarti, D., Kautsari, M. F., Sholichah, F., Purnomo,

A., \& Rosyidah, E. (2017). SMP SMA Al-Amin

Ponpes Bahrul Hidayah Serahkan pada Allah

Ta'ala. In Wirausaha Pendidikan Indonesia (Jilid

1). Sidoarjo: UNUSIDA Press. 